\title{
The Journal of Medical Resegirch
}

\section{Letter to Editor}

JMR 2017; 3(5): 212-213

September- October

ISSN: 2395-7565

(C) 2017, All rights reserved www.medicinearticle.com

Received: 23-10-2017

Accepted: 28-10-2017
*Corresponding author: Seyed Hossein Shahcheraghi 1 Infectious Diseases Research Center, Shahid Sadoughi University of Medical Sciences, Yazd, Iran

2 Department of Modern Sciences \& Technologies, Faculty of Medicine, Mashhad University of Medical Sciences, Mashhad, Iran

Tel: + 98-9132531389

E-mail:

shahcheraghih[at]gmail.com

\section{Anti-HIV effect of cervicovaginal secretions}

Seyed Hossein Shahcheraghi*1,2, Jamshid Ayatollahi' ${ }^{1}$, Marzieh Lotfi ${ }^{3}$, Razieh Akhondi $^{1}$, Mohammad Dehghan Niri ${ }^{4}$, Azam Fazilati ${ }^{5}$, Ehsan Hasanzadeh ${ }^{3}$

1 Infectious Diseases Research Center, Shahid Sadoughi University of Medical Sciences, Yazd, Iran

2 Department of Modern Sciences \& Technologies, Faculty of Medicine, Mashhad University of Medical Sciences, Mashhad, Iran

3 Faculty of Medicine, Shahid Sadoughi University of Medical Sciences, Yazd, Iran

2 Afshar Hospital, Shahid Sadoughi University of Medical Sciences, Yazd, Iran

3 Shahid Sadoughi Hospital, Shahid Sadoughi University of Medical Sciences, Yazd, Iran

\section{Abstract}

HIV/AIDS is the death cause worldwide for women of reproductive age, affecting 1.5 million pregnancies. The aim from this letter is investigating anti-HIV activity of cervicovaginal fluid.

Keywords: HIV/AIDS, Anti-HIV activity, Cervicovaginal fluid

\section{Dear Editor,}

HIV/AIDS is the leading cause of death worldwide for women of reproductive age, affecting 1.5 million pregnancies ${ }^{[1]}$. Infected females are main agents for transmission of HIV to uninfected males ${ }^{[1]}$.

The several vaginal factors decrease the rate of active HIV virions shed by infected women; therefore, these factors reduce HIV transmission to men. The mucosal lining of the epithelial barrier is the first defense line against virus acquisition in the female genital tract ${ }^{[2]}$.

It seems that in primates, IgG from the circulation is transported by a receptor-mediated act into the female genital tract secretions and contributes to almost one-half of the IgG pool in the secretions [2-5].

The antiviral act of cervicovaginal liquid is assumed to be conferred, in part, by the (Antiviral peptides) AMPs and chemokines ${ }^{[3,4]}$. The antiviral and antibacterial activities of lactobacilli have often been attributed to the ability of some species to generate hydrogen peroxide $\left(\mathrm{H}_{2} \mathrm{O}_{2}\right)$. Lactic acid production by lactobacilli may also have an indirect effect on transmission of HIV by potentially preventing BV, which is related to a high risk of HIV acquisition in both genders. On the other hand, some products such as acetic acid, propionic acid and butyric acid released by BV-associated bacteria increase inflammation and potentially activate target cells in the vagina known to increase HIV infection ${ }^{[3,5]}$.

Macrophage inflammatory protein (MIP)-3a, RANTES (regulated upon activation, normally T-cell expressed and secreted), human beta defensing (HBD)-2, elafin, and several other immune mediators are agents of related to protection against HIV $[3,5]$. Antimicrobial peptides, cytokines, and chemokines are also important effectors of innate immune protection within the female lower genital tract. Some recruit immune cells and others directly target microbes. Many of these molecules are known to have potent anti-HIV [6, 7]. Interestingly, majority of these mediators (including HBD-2, HBD-3, lactoferrin, LL-37, MIP3a, and RANTES) are suppressed during pregnancy, especially during the second and third trimesters $[3,5]$. 
There are many recognized principles in bioethics that apply to both clinical and research ethics about subject of letter. Respect for persons, beneficence, and justice are three main parameters. Respect for persons entails respecting the decisions of autonomous persons and protecting persons who lack decision-making capacity and therefore are not autonomous. It also imposes an obligation to treat persons with respect by maintaining confidences and keeping promises ${ }^{[8-10]}$.

Therefore, it is a main point to consider how the susceptibility of the lower genital tract to HIV acquisition may be changed in pregnancy, because the risk of perinatal transmission magnifies the effect of HIV on reproductive-age women.

\section{Acknowledgments}

The authors thank from Infectious Diseases Research Center of Shahid Sadoughi University of Medical Sciences. All authors contributed in writing of this article.

\section{REFERENCES}

1. Wei Q, Moldoveanu Z, Huang WQ, Alexander RC, Goepfert PA, Mestecky J. Comparative Evaluation of HIV-1 Neutralization in External Secretions and Sera of HIV-1-Infected Women. Open AIDS J. 2012; 6:293-302.

2. Aldunate M, Tyssen D, Johnson A, Zakir T, Sonza S, Moench T, et al. Vaginal concentrations of lactic acid potently inactivate HIV. J Antimicrob Chemother. 2013;68(9):2015-25.

3. Hughes BL, Dutt R, Raker C, Barthelemy M, Rossoll RM, Ramratnam $B$, et al. The impact of pregnancy on anti-HIV activity of cervicovaginal secretions. Am J Obstet Gynecol. 2016; 215(6):748.

4. Valore EV, Park CH, Igreti SL, Ganz T. Antimicrobial components of vaginal fluid. Am J Obstet Gynecol 2002; 187:561-568.

5. Ghosh M, Fahey JV, Shen Z, Lahey T, Cu-Uvin S, Wu Z, et al. Anti-HIV activity in cervical-vaginal secretions from HIV-positive and negative women correlate with innate antimicrobial levels and IgG antibodies. PLoS One. 2010; 5(6): 11366.

6. Anderson BL, Ghosh M, Raker C, Fahey J, Song Y, Rouse DJ, et al. In vitro anti-HIV-1 activity in cervicovaginal secretions from pregnant and nonpregnant women. Am J Obstet Gynecol. 2012; 207(1): 1-10.

7. Hattori S, Matsuda K, Kariya R, Harada H, Okada S. Proliferation of functional human natural killer cells with anti-HIV-1 activity in NOD/SCID/Jak3(null) mice. Microbiol Immunol. 2016; 60(2):106-13.

8. Guzzo C, Fox JC, Miao H, Volkman BF, Lusso P. Structural Determinants for the Selective Anti-HIV-1 Activity of the All- $\beta$ Alternative Conformer of XCL1. J Virol. 2015; 89(17):9061-7.

9. Madison MN, Roller RJ, Okeoma CM. Human semen contains exosomes with potent anti-HIV-1 activity. Retrovirol. 2014; 11:102.

10. Drannik AG, Nag K, Yao XD, Henrick BM, Ball TB, Plummer FA, et al. Anti-HIV-1 activity of elafin depends on its nuclear localization and altered innate immune activation in female genital epithelial cells. PLoS One. 2012; 7(12): 52738. 